\title{
Impact of improved crop production practices promoted in the Sudan Savannah Task Force (SSTF) of Katsina learning site
}

\author{
Ugbabe, 0. 0. ${ }^{1 *}$, Ahmed, B. ${ }^{1}$, Abdoulaye, T. $^{2}$ and Kamara, A. Y. ${ }^{2}$ \\ ${ }^{1}$ Institute for Agricultural Research, Ahmadu Bello University, Zaria, Nigeria. \\ 2International Institute of Tropical Agriculture, Ibadan, Nigeria. \\ *Corresponding author. Email: ougbabe@yahoo.com. Tel: +234 7038086122
}

Copyright $@ 2016$ Ugbabe et al. This article remains permanently open access under the terms of the Creative Commons Attribution License 4.0, which permits unrestricted use, distribution, and reproduction in any medium, provided the original work is properly cited.

Received 13th July, 2016; Accepted 18th August, 2016

\begin{abstract}
In Kano and Katsina States of Nigeria, some promoted improved crop production practices had been tested since 2008 in a series of farmer-managed field trials in four Innovation Platforms (two each) in these States representing the Sudan Savannah (SS) ecological zone of Nigeria. The objective of this study was to determine the impact of improved crop production practices of Sudan Savannah Task Force on the income and technical efficiency of the farming households in Katsina State. The study used primary data collected in 2011 cropping season with the aid of questionnaires. A total of 300 households were interviewed in the State. The tools used for analysis of the data were the double difference estimator and the stochastic production function. The result showed that the adopters of the introduced technologies enjoyed an increment of $744.35 \%$ in income. All the coefficients of the inputs in the production function were positive and statistically significant. The mean technical efficiency for the adopters and non-adopters were 0.87 and 0.65 respectively. The study concluded that the introduced technologies enhanced the income and efficiency in crop production of the adopters.
\end{abstract}

Keywords: Crop technologies, impact, promoted, superior, Sudan Savannah.

\section{INTRODUCTION}

Manual farm operations imposed severe limits on farmers' capacity to increase their farm sizes and productivity: the manual system of farming was technically inefficient, labour intensive, and costly to sustain (Olayemi et al., 2004). Although, the use of animal power for land cultivation had been adapted to a limited extent in the Savannah/Sahel belt of the country, its use in other areas was almost nonexistent for ecological and cultural reasons. It had been observed that mechanization of agriculture in the country has generally made little headway due to technical, ecological, and socioeconomic factors (Olayemi et al., 2004).

Temel et al. (2002) posited that the major outcome of the extensive consultations with numerous agricultural stakeholders in sub Saharan Africa established that the main impediment to the contribution of African agriculture to development lied in the way agricultural research was organized and conducted. The outcome led to the proposal of an alternative approach that aims to appropriately embed agricultural research within a larger system of innovation whereby knowledge from numerous sources were integrated and effectively put into use. One of the project aims was to evaluate the effectiveness of the Integrated Agricultural Research for Development (IAR4D) concept in its respective Agro-Ecological Zone (AEZ) by establishing Innovation Platform (IP) and conducting action research aimed at intensifying crop and livestock systems, improving access to markets and promoting sustainable management of the natural resource base. In pursuance of the goals of the project, a baseline survey was carried out in the Sudan Savannah 
zone in 2008 to provide baseline data on socio economics, resource use patterns, market opportunities, agricultural productivity and incidence of poverty in targeted project communities (Ayanwale et al., 2009).

Impact evaluation assessed the changes that could be attributed to a particular intervention, such as project, programme or policy, both the intended ones, as well as ideally the unintended ones (World Bank, 2008). In contrast to outcome monitoring, which examined whether targets had being achieved, impact evaluation was structured to answer the question: how would outcomes such as participants' wellbeing have changed if the intervention had not been undertaken? This involved counterfactual analysis that was "a comparison between what actually happened and what would had happened in the absence of the intervention (White, 2006)."

Impact evaluation helped us to answer key questions for evidence-based policy making: what worked, what did not, where, why and for how much? It had received increasing attention in policy making in recent years in both western and developing countries' contexts (Gertler et al., 2011). It was an important component of the armory of evaluation tools approaches and integral to global efforts to improve the effectiveness of aid delivery and public spending more generally in improving living standards. The literature about economic impacts of programme intervention emphasized the importance of establishing the appropriate counterfactual. As stated by Ravallion (1994), "the essential problem of impact evaluation was that we did not observe the outcomes for participants if they had not participated." The appropriate counterfactual facilitated measurement of the correct causal relationship between the technology and the outcomes being measured, because other confounding factors might also have influenced the outcome (Ravallion, 1994; Baker, 2000; Doss, 2000).

Ravallion (1994) summarized and compared the five main methods available for evaluating programme impact. Using randomization, individuals were selected into treatment and comparison groups at random, so that the only measurement errors were associated with sampling. Sampling errors could be reduced through larger samples. In the matching approach, the comparison group was matched to the treatment group based on characteristics measured in data from a larger, representative sample survey. Propensity scores were tabulated to support the selection of individuals. Reflexive comparisons enabled the "before and after" to be estimated for key parameters using a baseline, which served as the comparison group. With the double difference method, the treatment and comparison group were compared both before and after the treatment. The fifth approach was the instrumental variables approach. Instrumental variables were those that mattered to participation, but not to the outcome. They enabled the identification of exogenous variation in outcomes that could be attributed to the programme. The participation variable was the decision to use new crop hybrids.

The terms impact assessment or evaluations were often used interchangeably by many writers or authors, but the two were not the same. Impact referred to the broad, longterm economic, social and environmental effects resulting from project, while evaluation/assessment was judging, appraising or determining the worth, value or quality of project, in terms of its relevance, effectiveness, efficiency and impact (Impact Assessment and Evaluation Group, 1999). Impact assessment was an established practice in public goods investment project and programmes such as infrastructure, health, education, transportation, and urban development.

According to Arega et al. (2006), impact assessment of agricultural project was viewed as an important activity to ensure accountability, maintain credibility and improve internal decision-making processes together with the capability to learn from the past experience. Impact assessment was seen as a critical component of agricultural project that helped to define priorities of project and facilitated resource allocation among programmes, guided researchers and those involved in technology transfer to have a better understanding of the way new technologies were assimilated and diffused into farming communities, and showed evidence that clients benefit from the project products (Manyong et al., 2001). Impact studies was of great importance in agricultural research because it was used to identify alternative technologies that would address the major production constraints while at the same time taking into consideration farmers preferences and farming condition (Arega et al., 2006). Programme impacts referred to the set of results, such as changes in access to and quality of resources, changes in behaviour, or well -being that occurred at the beneficiary level and that could be directly attributed to programme activities and outputs.

Technical efficiency (TE) was the firm's ability to produce maximum output given a set of inputs and technology (Farrel, 1957). Technical efficiency was just one component of overall economic efficiency. Profit maximization required a firm to produce the maximum output given the level of inputs employed (technical efficiency), used the right mix of inputs in light of the relative price of each input (input allocative efficiency), and produced the right mix of outputs given the set of prices (output allocative efficiency) (Kumbhaker and Lovell, 2000). Generally, the gamma parameter $y=\sigma_{u}^{2}$ / $\sigma_{v}{ }^{2}$ lied between 0 and 1 ; with a value equal to 0 implying that technical inefficiency was not present and the ordinary least square estimation would be an adequate representation and a value close to 1 implying the frontier model appropriate (Piesse and Thirtle, 2000).

The double difference estimator was used to determine the impact of improved crop production practices of SSTF on the income of the farming households in the study 
area while the stochastic production function was used to evaluate the impact of improved crop production practices of SSTF on the technical efficiency of the farming households. The double difference estimator was used for the impact analysis because there was enough baseline data. The project was on for over ten years. The authors made some brief references to other methods that could be used to achieve programme impacts to create the awareness of their availability to the readers. Although, there are different functional forms of stochastic frontier, the data was fitted to Cobb-Douglas and translog functional forms and the most preferred functional form was selected based on the result of generalized likelihood ratio test. The overall aim of this study was to determine the impact of improved crop production practices of the Sudan Savannah Task Force on the income and technical efficiency of the farming households in Katsina State, Nigeria, which the study achieved.

\section{MATERIALS AND METHOD}

The sampling design adopted for the study was multistage stratified random sampling. A two stage sampling design was followed; in the first stage, villages in the participating Local Government Areas for intervention and non-participating Local Government Areas (LGAs) for both conventional and clean LGAs were selected and then farmers sampled. A conventional LGA is a non-intervention/counterfactual LGA with some research and development activities by other organizations currently going on at the time of the study. Clean LGA is also a non-intervention/counterfactual LGA with no current research and development activities by other organizations going on at the time of the study. The non-participating LGAs served as counterfactuals to intervention LGAs. The sample was also stratified, at the first stage between villages where there were on-going platform activities and villages without platform activities. For each participating LGA the list of all the participating villages were made. The same was done for each nonparticipating LGAs. Five villages were selected from the list of participating (intervention) and non-participating (conventional and clean) LGAs randomly using a table of random numbers. In the second stage, the same procedures applied in the sampling of villages were also followed in selecting farmers' samples. From each of the sampled villages, lists of crop farmers were made with the assistance of Agricultural Development Project staff and then ten farmers selected using systematic random sampling method. Ten farmers were also selected using systematic random sampling method from the conventional and clean villages. The total sample size was 300 and consisted of adopters (137) and nonadopters (163) as shown in Table 1. The platform activities were established to foster interaction among a range of stakeholders and strengthen capacity of stakeholders to generate, apply and share knowledge. The type of food crops that are produced by the farmers on the platforms are maize, sorghum, millet, cowpea, groundnut and soybean. The geographical coordinates of the study area (Katsina State, Nigeria) is Latitude $12^{\circ} 15^{\prime} \mathrm{N}$ and Longitude $7^{\circ} 30^{\prime} \mathrm{E}$.

\section{Analytical Technique}

The double difference estimator and the stochastic production function were used in the analysis of this project.

\section{The double difference estimator}

To use this model, information on both adopters of SSTF crop production practices and non- adopters were required for before and after programme intervention. The Verners model adapted for this study was specified in equation (1).

$$
D D=\left[\left(\frac{1}{N_{A}} \sum_{1=i}^{N_{A}}\left(\bar{Y}_{1}^{A}-\bar{Y}_{0}^{A}\right)\right)-\left(\frac{1}{N_{N A}} \sum_{1=j}^{N_{N A}}\left(\bar{Y}_{1}^{N A}-\bar{Y}_{0}^{N A}\right)\right)\right] \ldots(1)
$$

Where; $\bar{Y}_{0}^{A}=$ average income $(\mathbb{A})$ of the adopters before the intervention, $\bar{Y}_{1}^{A}=$ average income $(\mathrm{N})$ of the adopters after the intervention, $\bar{Y}_{0}^{N A}=$ average income $(\mathbb{N})$ of the nonadopters before the intervention, $\bar{Y}_{1}^{N A}=$ average income $(\mathbb{N})$ of the non-adopters after the intervention, $N_{A}=$ number of adopters, $N_{N A}=$ number of non-adopters and DD = the difference between the average changes in the income for the adopters and non-adopters.

It was common to find difference in difference estimators presented in a table format, and for this study; the format was presented in (Table 2).

T-test as was used to validate the Double Difference Analysis.

$$
\begin{aligned}
& \mathrm{t}=\frac{\overline{\mathrm{X}}_{1}-\overline{\mathrm{X}}_{2}}{\mathrm{SE}} \ldots \ldots \ldots \ldots \ldots \ldots \ldots \ldots \ldots \ldots \ldots \ldots \ldots \ldots \\
& \text { Coefficient of Variation }(\mathrm{CV})
\end{aligned}
$$

Where: $S E=$ Standard error, $\bar{X}_{1}$ and $\bar{X}_{2}$ were sample means of the two groups, $S t d=S t a n d a r d$ deviation for a group and $N=$ Sample size for a group.

\section{Cobb-Douglass frontier production function}

The production technology of the farmer was assumed to be specified by the Cobb-Douglass frontier production 
Table 1. Distribution of respondents by LGAs, Villages and Treatments.

\begin{tabular}{|c|c|c|c|c|c|c|}
\hline LGA & Villages & Treatment & $\begin{array}{l}\text { Participating/ } \\
\text { Non- Participating }\end{array}$ & No. of Respondents & A & NA \\
\hline \multirow{5}{*}{ Safana } & Kunamawa A & Intervention & Participating & 10 & 10 & 0 \\
\hline & Kanbiri & Intervention & Participating & 10 & 10 & 0 \\
\hline & Dogon Ruwa & Intervention & Participating & 10 & 10 & 0 \\
\hline & Mai Jaura & Intervention & Participating & 10 & 10 & 0 \\
\hline & Kwamawa B & Intervention & Participating & 10 & 9 & 1 \\
\hline \multirow{5}{*}{ Musawa } & Jimkashi & Intervention & Participating & 10 & 10 & 0 \\
\hline & Tabbani & Intervention & Participating & 10 & 10 & 0 \\
\hline & Bakan & Intervention & Participating & 10 & 9 & 1 \\
\hline & Yarkanya & Intervention & Participating & 10 & 9 & 1 \\
\hline & Gin-Gin & Intervention & Participating & 10 & 9 & 1 \\
\hline \multirow{10}{*}{ Dan } & Garaji & Clean & Non-participating & 10 & 2 & 8 \\
\hline & Barza & Clean & Non-participating & 10 & 1 & 9 \\
\hline & Tasha kaura & Clean & Non-participating & 10 & 1 & 9 \\
\hline & Chakau & Clean & Non-participating & 10 & 2 & 8 \\
\hline & Yantumaki & Clean & Non-participating & 10 & 4 & 6 \\
\hline & Sanawa & Conventional & Non-participating & 10 & 2 & 8 \\
\hline & Nasarawa & Conventional & Non-participating & 10 & 2 & 8 \\
\hline & Shema & Conventional & Non-participating & 10 & 1 & 9 \\
\hline & Shantalawa & Conventional & Non-participating & 10 & 2 & 8 \\
\hline & Karofi & Conventional & Non-participating & 10 & 5 & 5 \\
\hline \multirow{10}{*}{ Ingawa } & Yandoma & Clean & Non-participating & 10 & 0 & 10 \\
\hline & Kandawa & Clean & Non-participating & 10 & 0 & 10 \\
\hline & Gamda & Clean & Non-participating & 10 & 0 & 10 \\
\hline & Kurfeji & Clean & Non-participating & 10 & 1 & 9 \\
\hline & Irawa & Clean & Non-participating & 10 & 2 & 8 \\
\hline & Yargora & Conventional & Non-participating & 10 & 3 & 7 \\
\hline & Masibil & Conventional & Non-participating & 10 & 0 & 10 \\
\hline & Manomawa & Conventional & Non-participating & 10 & 3 & 7 \\
\hline & Shibdawa & Conventional & Non-participating & 10 & 5 & 5 \\
\hline & Gobirawa & Conventional & Non-participating & 10 & 5 & 5 \\
\hline Total & 30 & & & 300 & 137 & 163 \\
\hline
\end{tabular}

Note: $\mathrm{A}=$ Adopters, and NA = Non-Adopters.

Table 2. Double difference estimate of the impact of adoption of SSTF improved crop production practices on farmers' income.

\begin{tabular}{lccc}
\hline & Pre Intervention & Post Intervention & Difference between periods \\
\hline Adopters & $\overline{\mathrm{Y}}_{0}^{\mathrm{A}}$ & $\overline{\mathrm{Y}}_{1}^{\mathrm{A}}$ & $\overline{\mathrm{Y}}_{1}^{\mathrm{A}}-\overline{\mathrm{Y}}_{0}^{\mathrm{A}}$ \\
Non-adopters & $\overline{\mathrm{Y}}_{0}^{\mathrm{NA}}$ & $\overline{\mathrm{Y}}_{1}^{\mathrm{NA}}$ & $\overline{\mathrm{Y}}_{1}^{\mathrm{NA}}-\overline{\mathrm{Y}}_{0}^{\mathrm{NA}}$ \\
Difference between groups & $\overline{\mathrm{Y}}_{0}^{\mathrm{A}}-\overline{\mathrm{Y}}_{0}^{\mathrm{NA}}$ & $\overline{\mathrm{Y}}_{1}^{\mathrm{A}}-\overline{\mathrm{Y}}_{1}^{\mathrm{NA}}$ & $\overline{\mathrm{Y}}_{1}^{\mathrm{A}}-\overline{\mathrm{Y}}_{1}^{\mathrm{NA}}-\left(\overline{\mathrm{Y}}_{0}^{\mathrm{A}}-\overline{\mathrm{Y}}_{0}^{\mathrm{NA}}\right)$ \\
\hline
\end{tabular}

function as described by Tadesse and Krishnamoorthy (1997). The function was described as:

$\operatorname{Ln} Y \mathrm{i}=\mathrm{B}_{0}+\mathrm{B}_{1} \operatorname{Ln} \mathrm{X}_{1}+\mathrm{B}_{2} \operatorname{Ln} \mathrm{X}_{2}+\mathrm{B}_{3} \operatorname{Ln} \mathrm{X}_{3}+\mathrm{B}_{4} \operatorname{Ln} \mathrm{X}_{4}+\mathrm{V}_{\mathrm{i}}-\mu_{\mathrm{i}} \cdots(3)$

Where; Subscript i referred to the $i^{\text {th }}$ farmer in the sample,
Ln Denoted the natural logarithm (base e), $Y=$ Value of the output (Crop in Naira), $x_{1}=$ Farm size (ha), $x_{2}=$ Seed in grain equivalent $(\mathrm{kg})$ because we had up to five crops (maize, sorghum, millet, cowpea, groundnut and soybean), $x_{3}=$ Labour (man-hour), $x_{4}=$ Fertilizer $(\mathrm{kg}), V_{i}=$ Error term, which were assumed iid (independent and identically 
Table 3. Double difference estimate of the impact of adoption of SSTF improved crop production practices on farmers' mean annual income ( $\left.\mathrm{A}^{\prime} \mathrm{OO}\right)$.

\begin{tabular}{lccc}
\hline Parameters & Pre Intervention & Post Intervention & Difference between income at different periods \\
\hline \multirow{2}{*}{ Adopters } & 2356.83 & 19900 & 17543.17 \\
& $(177.77)$ & $(1779.04)$ & $(1367.07)^{\star}$ \\
Non-adopters & 2448.98 & 5298.72 & 2849.74 \\
& $(159.14)$ & $(448.01)$ & $(1426.06)$ \\
Difference between groups & -92.15 & 14601.28 & 14693.43 \\
& $(6.29)$ & $(1027.11)$ & $(1631.52)^{\star}$ \\
\hline
\end{tabular}

Note: * indicates significant at $1 \%$ level. Figures in brackets were the standard errors.

Table 4. T-test result of adopters versus non-adopters in relation to income.

\begin{tabular}{lcc}
\hline Estimate & Adopters $\left(\mathbf{X}_{1}\right)$ & Non- Adopters $\left(\mathbf{X}_{2}\right)$ \\
\hline Observation & 137 & 163 \\
Maximum & $10,500,000$ & 436,950 \\
Minimum & 18,110 & 20,600 \\
Average & 760,515 & 252.169 \\
Standard deviation & 1116796.83 & 106052.9 \\
Coefficient of variation & 1.47 & 0.42 \\
Differential & 508,346 & \\
Standard error & 103721.09 & \\
$\mathrm{t}-$ value & $4.90^{*}$ & \\
\hline${ }^{*} \mathrm{P}<0.01$. & &
\end{tabular}

distributed) with mean zero and constant variance and independent of $\mu_{\mathrm{i}}$ and $\mu_{i}=$ Non-negative random variable associated with technical inefficiency in production.

The technical inefficiency effects $\mu$ was defined by:

$\mu=Z_{0}+\hat{\mathrm{O}}_{1} Z_{1 i}+\hat{\mathrm{O}}_{2} Z_{2 i}+\hat{\mathrm{O}}_{3} Z_{3 i}+\hat{\mathrm{O}}_{4} Z_{4 i}+\hat{\mathrm{O}}_{5} Z_{5 i}+\hat{\mathrm{O}}_{6} Z_{6 i} \cdots \cdots$ (4)

Where: $Z_{0}, Z_{1}, Z_{2}, Z_{3}, Z_{4}, Z_{5}$ and $Z_{6}$ represented, intercept, age, household size, years of experience in farming, educational level, extension contact and annual income respectively. These were included in the model to indicate their possible influence on the technical efficiencies of the farmers.

\section{RESULTS AND DISCUSSION}

The adopters of the crop production practices introduced by the SSTF enjoyed a very high increase of $744.35 \%$ in their income (from $N 235,683$ to $N 1,990,000$ ), resulting in a difference of income between the post intervention and pre intervention periods of $\mathrm{N1}, 754,317$ which was significant at $1 \%$ (Table 3). The non-adopters had an increment of N284, 974 in their income within the same period of time and were not statistically significant. The project thus had positive impact on the income of the farming households in the study area.
T-test was employed to determine the impact of adopting SSTF recommended crop production practices on farmers' income. The pool data of the on-farm income was disaggregated into adopters and non-adopters for comparison. The result of the T-test (Table 4) indicated that there was significant difference between adopters and non-adopters in relation to income level at $1 \%$ level of probability. The Coefficient of variation (CV) in the income was calculated to investigate the level of variation in income. The CV of adopters and non-adopters were 1.47 and 0.42 , respectively. This indicates that there exists less variation in income among the non-adopters than adopters (Table 4). This might be due to small land area put into cultivation of these crops and the low output from production by these non-adopters, which might not be statistically significant.

\section{Impact of Adoption of Recommended SSTF Crop Production Practices on Technical Efficiency of Farmers}

The estimation of the Cobb-Douglas stochastic production function simultaneously with the technical inefficiency effects in Equation (3) (Coelli, 1996) generated the results shown in Table 5. The value of $\mathrm{Y}$ $=0.899$ was statistically significant at the $1 \%$ level, which 
Table 5. Maximum likelihood estimates of the Cobb-Douglas stochastic frontier production function (dependent variable Iny=Ingrains equivalent (GE) of total output in $\mathrm{kg}$ ).

\begin{tabular}{lcccc}
\hline Variables & Parameters & Coefficient & Standard error & T - values \\
\hline Stochastic frontier & & & & \\
Constant & $\beta_{0}$ & $7.240^{*}$ & 0.166 & 43.738 \\
In Farm size $\left(\mathrm{X}_{1}\right)$ & $\beta_{1}$ & $0.367^{*}$ & 0.035 & 10.446 \\
In Seed GE $\left(\mathrm{X}_{2}\right)$ & $\beta_{2}$ & $0.112^{*}$ & 0.043 & 2.625 \\
In labour $\left(\mathrm{X}_{3}\right)$ & $\beta_{3}$ & $0.072^{*}$ & 0.028 & 2.591 \\
In Fertilizer $\left(\mathrm{X}_{4}\right)$ & $\beta_{4}$ & $0.044^{*}$ & 0.011 & 3.858 \\
Inefficiency model & & & & \\
Constant & & & & \\
Age of farmer (years) & $\alpha_{0}$ & -1.527 & 8.776 & -0.174 \\
Household size & $\alpha_{1}$ & 0.129 & 0.402 & 0.321 \\
Farming experience $(Y e a r s)$ & $\alpha_{2}$ & 0.026 & 0.088 & 0.297 \\
Education (Years) & $\alpha_{3}$ & $-0.060^{*}$ & 0.018 & -3.301 \\
Extension visit dummy & $\alpha_{4}$ & $0.112^{* *}$ & 0.047 & 2.379 \\
Annual Income ( $\mathrm{N})$ & $\alpha_{5}$ & $-0.340^{*}$ & 0.050 & -6.783 \\
& $\alpha_{6}$ & $-0.563^{*}$ & 0.159 & -3.542 \\
Variance Parameters & & & & \\
Sigma squared & & & & \\
Gamma & $\sigma^{2}$ & $0.150^{*}$ & 0.041 & 3.657 \\
Log likelihood function & $\mathrm{Y}$ & $0.899^{*}$ & 0.269 & 3.347 \\
Number of observations & $\mathrm{N}$ & -188.446 & & \\
Mean Technical Efficiency & $\overline{T E}$ & 300 & & \\
\hline *P<0.01, ${ }^{* *} \mathrm{P}<0.5 ; \mathrm{x}^{2}=39.67(\mathrm{P}<0.01)$. & 0.801 & &
\end{tabular}

implies that about $90 \%$ of the residual grains production by the sampled farmers was due to the inefficiency effect. The sigma squared $\left(\sigma^{2}=\sigma_{u}^{2} / \sigma_{v}^{2}\right)$ was also significant at $1 \%$ level of probability, indicating a good fit and the correctness of the specified half normal distributional assumption made on the efficiency error term.

Automatically, the analysis generated result of the hypothesis that states that there was no any measurable inefficiency in grains production among the sampled farmers. The one-sided generalized likelihood ratio tests of $\mathrm{Y}=0$ generated a statistic of 39.67 distributed as $\mathrm{X}^{2}$ with eight degrees of freedom, which was statistically significant at $1 \%$ level, indicating that the average production function was not a suitable specification of grains production and technical efficiency effects were not random errors. Thus, there was some measurable inefficiency in grains production among the sampled farmers.

All the coefficients of the inputs in the production function were positive and statistically significant at the $1 \%$ level, implying direct relationship between each of the inputs and grains output. The production elasticities for all the inputs had the expected positive signs. This result implied that $1 \%$ increase in seed in grains equivalent, labour and fertilizer increased yield by $0.11 \%, 0.06 \%$ and
$0.04 \%$ respectively. Among the three production inputs, seed had the highest impact on yield. This was due to the fact that yield was directly depended on the number of plants per hectare, and population of plants was directly related to the quantity of seed used. The estimated return to scale was 0.596 , land inclusive, which implied a decreasing return to scale existed in grains production in the study area. Therefore, an increase in all production inputs by $1 \%$ increased grains yield by less than $1 \%$, ceteris paribus.

The average technical efficiency for the sampled grains farmers in the study area was 0.801 (Table 5). This implied that on the average, the farmers were able to obtain over $80 \%$ of potential output from a given mix of production inputs. Thus, in a short run, there was a room for increasing grains production by about $20 \%$, by adopting the technology and techniques used by the best farmers.

This section also reported on determinants of technical inefficiency estimated in the Table 5. The inefficiency model was specified in equation (4). Generally, a negative sign on a parameter meant that the variable reduced technical inefficiency, while a positive sign increased technical inefficiency. The results on Table 5 showed that farming experience, extension visit and 
Table 6. Frequency distribution of technical efficiency estimates for treatment and counterfactual farmers.

\begin{tabular}{|c|c|c|c|c|}
\hline \multirow{2}{*}{ Efficiency Range } & \multicolumn{2}{|c|}{ Treatment } & \multicolumn{2}{|c|}{ Counterfactual } \\
\hline & Frequency & Percentage (\%) & Frequency & Percentage (\%) \\
\hline $25-35$ & - & - & 4 & 2.45 \\
\hline $36-45$ & - & - & 9 & 5.52 \\
\hline $46-55$ & - & - & 11 & 6.75 \\
\hline $56-65$ & 2 & 1.46 & 23 & 14.11 \\
\hline $66-75$ & 19 & 13.87 & 53 & 32.52 \\
\hline $76-85$ & 47 & 34.31 & 63 & 38.65 \\
\hline$\geq 86$ & 69 & 50.36 & - & - \\
\hline Total & \multicolumn{2}{|c|}{137100} & \multicolumn{2}{|c|}{163100} \\
\hline Maximum TE & \multicolumn{2}{|c|}{0.92} & \multicolumn{2}{|c|}{0.83} \\
\hline Minimum TE & \multicolumn{2}{|r|}{0.59} & \multicolumn{2}{|r|}{0.28} \\
\hline Mean TE & \multicolumn{2}{|r|}{0.87} & \multicolumn{2}{|r|}{0.65} \\
\hline
\end{tabular}

average annual income had negative signs, and therefore reduced technical inefficiency (or increased technical efficiency) while age of farmers, household size and years of schooling had positive signs, implying that they increased technical inefficiency. The negative sign on farming experience variable indicated that an increase in the number of years in grains production decreased technical inefficiency; this relationship was significant at the $1 \%$ level. This was consistent with the findings of Ojo and Ajibefun (2000).

The years of schooling variable had a positive sign and statistically significant at $5 \%$ level of significance. This indicated that level of education attained reduced technical efficiency. This could probably be explained by the fact that high level of education reduces the desire for farming, therefore the farmers probably devoted much of their time on paid income employment instead. This was consistent with the findings of Ojo (2003) and Usman (2009). Extension visit had a negative sign. This agreed with the a priori expectation that access to extension agents was positively correlated to adoption of improved technology and techniques of production which improved technical efficiency. This finding was consistent with the result of Usman (2009), who found that extension visit increases technical efficiency in sesame production in Jigawa State.

Average annual income in Naira was found to be significant at $1 \%$ level of probability and negatively related to inefficiency. Higher income usually boosted farmers' purchasing powers to enable them acquire modern and improved technologies for their farm production. This will lead to increase in their technical efficiency.

\section{Frequency distribution of technical efficiency scores}

The frequency distribution of the technical efficiency estimates obtained from the stochastic frontier model for each farmer was disaggregated into adopters and nonadopters (Table 6). The minimum and maximum technical efficiency estimates for the adopters were 0.59 and 0.92 , while those of non-adopters were $0.28,0.83$ respectively. The mean technical efficiency for the adopters and non-adopters were 0.87 and 0.65 respectively. This implied that the adopters were more technically efficient than the non-adopters. Only $13 \%$ of the potential yields were lost due to inefficiency in grains production by adopters while $35 \%$ of the potential yields were lost by non-adopters. In the short run, there was a scope for increasing grains production by $13 \%$ and $35 \%$ by adopters and non-adopters respectively by adopting technologies and techniques used by the best practice grains farms. Over $50 \%$ of the farms of the adopters operated at more than $85 \%$ efficiency level while none of the non-adopters' farms had TE that exceeded $85 \%$.

\section{Conclusion and recommendation}

The study concludes that the introduced technologies enhanced the income of adopters by $744.35 \%$. The adopters of the technologies were more technically efficient in crop production (with a mean technical efficiency of $87 \%$ ) than the non-adopters (with a mean technical efficiency of $65 \%$ ). It was recommended that strong linkages should be established between farmers and seed/fertilizer sources to improve their timely availability, and also government should construct good access roads that will ease the transportation of crop outputs to major markets in the study areas. This is to address the farmers' main problems of timely availability and affordability of major crop production inputs like hybrid seeds, inorganic fertilizers and agrochemicals. Good access roads enhance the market value of crops produced by the farmers. 


\section{CONFLICT OF INTEREST}

The authors declare that they have no conflict of interest.

\section{REFERENCES}

Arega, A., Manyong, V. M., Gockowski, J., Coulibaly, O., \& Abele, S. (2006). A Framework for Conceptualising Impact Assessment and Promoting Impact Culture in Agricultural Research. International Institute of Tropical Agriculture, Pp. 130.

Ayanwale, A., Abdoulaye, T. B., Ayedun, B., \& Akinola, A. (2009). Baseline report of the sudan Savannah zone of the Kano-Katsina-Maradi (KKM) Project Learning Site (PLS) of the Sub-Saharan Africa Challenge Programme (SSA CP). International Institute of Tropical Agriculture Press, Ibadan. Pp. 1-57.

Baker, J. (2000). Evaluating the Impact of Development Projects on Poverty: A Handbook for Practitioners. Washington, D.C: World Bank: p. 10.

Coelli, T. (1996). A guide to FRONTIER Version 4.1: A Computer Programme for Stochastic Frontier Production and Cost Function Estimation". CEPA Working Paper 96/07, University of New England, Armidale, Australia.

Doss, C. R. (2003). Understanding Farm Level Technology Adoption: Lessons Learned from CIMMYT's Micro Surveys in Eastern Africa. International Maize and Wheat Improvement Centre (CIMMYT). Economics Working Paper, 3(7). Mexico.

Farrel, J. M. (1957). The Measurement of Productive Efficiency. Journal of Royal Statistics, 120(3), 253-290.

Gertler, P. J, Martinez, S, Premand, P, Rawlings, L. B., \& Vermeersch, C. M. J. (2011). Impact Evaluation in Practice. World Bank. Washington DC.

Impact Assessment and Evaluation Group. (1999). Impact Assessment of Agricultural Research; Context and the Art. Paper presented at ASARECAIECARTICTA Workshop on Impact Assessment of Agricultural Research in Eastern and Central Africa, Entebbe, Uganda, 16-19 November, Pp. 1521.

Kumbhaker, S. C., \& Lovell, C. A. K. (2000). Stochastic Frontier Analysis. Cambridge: Cambridge University Press.

Manyong, V. M., Douthwaite, B., Coulibaly, O., \& Keatinge, J. D. H. (2001). Participatory Impact Assessment at the International Institute of Tropical Agriculture; Functions and Mechanism (Annex). in The Future of Impact Assessment in the CGIAR: Needs, Constraints and Options. Proceedings of a workshop organised by the standing panel on Impact Assessment of Technical Advisory Committee, 3-5, May, 2000. FAO, Rome, Italy, Pp. 69-74.
Ojo, S. O. (2003). Productivity and Technical Efficiency of Poultry Egg Production in Nigeria. International Journal of Poultry Science, 2(6), 459-464.

Ojo, S. O., \& Ajibefun, I. A. (2000). Effects of Training on Labour Productivity and Efficiency in Oil Palm Production in Ondo State, Nigeria. Journal of Sustainable Agriculture and Environment, 2, 275-279.

Olayemi, J. K., Fadahunsi, A., \& Adejobi, A. O. (2004). The Challenge of Building Democratic, Sustainable Peasants' Societies for a Developed Nigeria. Technical report presented at the Third World Forum Workshop, CESAG, 2-5 November, 2004, Dakar, Senegal.

Piesse, J., \& Thirtle, C. (2000). A Stochastic Frontier Approach to Firm Level Efficiency, Technological Change, and Productivity during the Early Transition in Hungary. Journal of Comparative Economics, 28, 473-501.

Ravallion, M. (1994). Poverty Comparisons. Fundamentals of Pure and Applied Economics. Harwood Academic, 56, 4.

Tadesse, B., \& Krishnamoorthy, S. (1997). Technical efficiency in paddy farms of Tamil Nadu: An analysis based on farm size and Ecological Zone. Agricultural Economics, 16, 185192.

Temel, T, Janssen, W., \& Karimov, F. (2002). The Agricultural Innovation System of Azerbaijan: An Assessment of Institutional Linkages. Country Report 64, International Service for National Agricultural Research, The Hague.

Usman, S. (2009). Analysis of Farm Plan and Resource Use Efficiency in Sesame Production in Jigawa State, Nigeria. M.Sc Thesis, Department of Agricultural Economics and Rural Sociology, Ahmadu Bello University, Zaria, 189pp.

White, H. (2006). Impact Evaluation: The Experience of the Independent Evaluation Group of the World Bank. World Bank. Washington DC: 3 . World Bank poverty group on impact evaluation. Washington DC. USA.

World Bank (2008). World Bank Poverty Group on Impact Evaluation. Washington DC. USA. 